\title{
Chiral discrimination of amlodipine from pharmaceutical products using capillary electrophoresis
}

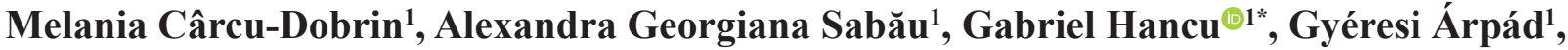 \\ Aura Rusu ${ }^{\oplus 1}$, Hajnal Kelemen ${ }^{\circledR}$, Lajos Attila Papp ${ }^{1}$, Anca Cârje ${ }^{2}$ \\ ${ }^{1}$ Department of Pharmaceutical Chemistry, Faculty of Pharmacy, University of Medicine and Pharmacy, Tîrgu Mureş, \\ Romania, ${ }^{2}$ Department of Analytical Chemistry and Drug Analysis, Faculty of Pharmacy, University of Medicine and \\ Pharmacy, Tîrgu Mureş, Romania
}

\begin{abstract}
The present work describes the development of a capillary electrophoresis (CE) method for the chiral discrimination of amlodipine (AML) enantiomers using cyclodextrine (CD) derivatives as chiral selectors. A large number of native and derivatized, neutral and ionized CD derivatives were screened to find the optimal chiral selector; and carboximethyl- $\beta-C D(C M-\beta-C D)$ was selected for the enantiomeric discrimination. A factorial analysis study was performed by orthogonal experimental design in which several factors were varied at the same time to optimize the separation method. The optimized method (25 mM phosphate buffer, $\mathrm{pH}=9.0,15 \mathrm{mM} \mathrm{CM}-\beta-\mathrm{CD}, 15^{\circ} \mathrm{C},+25 \mathrm{kV}, 30 \mathrm{mbar} / 1 \mathrm{~second}$, detection wavelength $230 \mathrm{~nm}$ ) was successfully applied for the baseline separation of AML enantiomers within 5 minutes. Successful validation and application of the proposed CE method suggest its routine use in enantioselective control of AML in pharmaceutical preparations.
\end{abstract}

Keywords: Amlodipine. Capillary electrophoresis. Chiral separation. Cyclodextrine. Experimental design.

\section{INTRODUCTION}

Amlodipine (AML) [(RS)-3-ethyl 5-methyl 2-[(2-aminoethoxy)methyl]-4-(2-chlorophenyl)-6-methyl1,4-dihydropyridine-3,5-dicarboxylate] (Figure 1) is a long-acting, dihydropyridine-type inhibitor of the slow calcium channel, used in the treatment of hypertension and angina pectoris. AML is a chiral substance and is used in therapy currently as a racemate (Murdoch, Heel, 1992).

However, the two enantiomers, $R(+)$-AML and $S(-)$-AML do not have the same pharmaceutical activity; the calcium channel blocking activity and consequently the vasodilatating properties residing primarily in the S(-)-AML enantiomer (Luksa et al., 1997).

From the above mentioned facts, it is obvious, that the development of new enantioselective analytical methods are required for pharmacodynamic and pharmacokinetic studies but also for the control of enantiomeric composition of pharmaceuticals preparations containing AML.

\footnotetext{
*Correspondence: G. Hancu . Department of Pharmaceutical Chemistry, Faculty of Pharmacy, University of Medicine and Pharmacy, Gh. Marinescu 38, 540139, Tîrgu Mureș, Romania. E-mail: gabriel.hancu@umftgm.ro
}

Chromatographic methods have long been the first choice methods for the enantioseparation of AML. In the past few years, liquid chromatography-mass spectrometry (LC-MS) was applied for quantification of AML enantiomers in human plasma (Hotha et al., 2013) and AML enantiomers were separated by LC on a molecularly imprinted polymer-based stationary phase (Li et al., 2013). AML enantiomers were also separated by achiral HPLC, utilizing a dual chiral mobile phase additive system composed of sulfobutylether- $\beta$-cyclodextrin (SBE- $\beta-C D)$ and polyethylene glycol 20000 (PEG-20) (Xie et al., 2014).

Nowadays, capillary electrophoresis (CE) represents an alternative and a complementary method to the more frequently used chromatographic techniques in the chiral analysis of pharmaceutical substances (Deeb et al., 2016). The advantages of CE in chiral analysis are related to the rapid method development, high separation efficiency, low consumption of analytes, solvents and chiral selectors and especially with the high selectivity in choosing and changing the chiral selector. Also in CE usually a direct method of separation is used by simply adding the chiral selector to the buffer electrolyte (Deeb et al., 2014). 
The most frequently used chiral selectors in CE are the cyclodextrins (CDs); cyclic oligosaccharides with truncated cylindrical molecular shapes, having a hydrophilic outside surface and a hydrophobic internal cavity, which can include compounds fitting their cavities by hydrophobic interactions (Scriba, Jac, 2013).

There are quite a few published CE methods for the chiral separation of AML enantiomers, most of them using cyclodextrins (CD) as chiral selectors. AML enantiomers separation by CE was resolved using different types of CD: native $\alpha-C D$ (Small et al., 1995); derivatized neutral HP- $\alpha$-CD (Fakhari et al., 2008), HP- $\beta-C D$ (Owens et al., 1998; Wang et al., 2007) and M- $\beta-C D$ (Hancu et al., 2015 ); derivatized anionic SBE- $\beta-C D$ (Owens et al., 1998 ) and HS- $\beta-C D$ (Zandkarimi et al., 2009). In another study an on-line coupled capillary isotachophoresis (ITP) - capillary zone electrophoresis (CZE) method using HP- $\beta C D$ as chiral selector was used for the direct quantitative enantioselective determination of AML in human urine (Mikus et al., 2008). Also a combined chiral selector system containing a neutral polysaccharide (glycogen), a ionic polysaccharide (chondroitin sulfate), $\beta-C D$ and HP- $\beta-C D$, respectively, exhibited good enantioselective properties towards AML enantiomers analysis (Chen et al., 2010). As an alternative to CDs maltodextrin was successfully used as chiral selector in CE for the enantioseparation of AML from pharmaceuticals (Nojavan et al., 2014). Also, polybrene, a cationic polymer, was used to improve AML enantioseparation by CE (Zandkarimi et al., 2012).

The purpose of our study was to develop a new alternative CE method which is suitable to determine amlodipine enantiomers from pharmaceutical products.

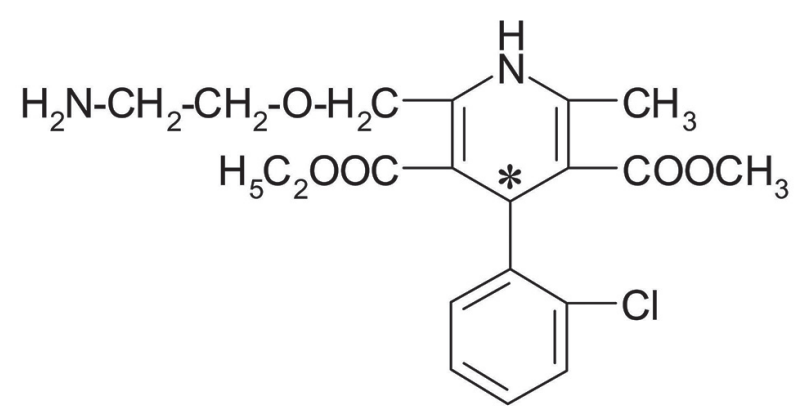

FIGURE 1 - Chemical structure of AML (* denotes the chiral center).

\section{MATERIAL AND METHODS}

\section{Instrumentation}

CE determinations were performed on an Agilent
1600 CE system (Agilent, Waldbronn, Germany) equipped with a DAD detector. Data were collected using Chemstation 7.01 (Agilent, Waldbronn, Germany) software. Separations were performed using a $48 \mathrm{~cm}$ length (40 cm effective length) x $50 \mu \mathrm{m}$ I.D silicafused capillary (Agilent, Waldbronn, Germany). $\mathrm{pH}$ measurements were performed on a Terminal $740 \mathrm{pH}$ meter (Inolab, Germany).

\section{Chemicals and reagents}

$(R, S)$-amlodipine besilate and $S$-amlodipine besilate were acquired from Moehs Catalana (Barcelona, Spain); the two analytes were of pharmaceutical grade. Phosphoric acid $(85 \%)$, disodium hydrogenophosphate, sodium didydrogenophosphate were purchased form Merck (Darmstadt, Germany), sodium hydroxide from Lach Ner (Neratovice, Czech Republic) while methanol from Chemical (Bucharest, Romania). All reagents were of analytical grade. Purified water was provided by a Milli-Q Plus water purification system (Millipore, USA).

The following CDs were used as chiral additives: native neutral CDs $(\beta-C D, \gamma-C D)$, derivatized neutral CDs (hydroxypropyl- $\beta-\mathrm{CD}-\mathrm{HP}-\beta-\mathrm{CD}$, methylated $\beta-\mathrm{CD}-\mathrm{M}-\beta-\mathrm{CD}$, heptakis (2,6-di- $O$-methyl)- $\beta-\mathrm{CD}$ DIMEB, heptakis(2,3,6-tri- $O$-methyl)- $\beta$-CD - TRIMEB), derivatized ionizable CDs (carboxymethyl- $\beta-C D$ CM- $\beta-C D$, sulfobuthylether- $\beta-C D$ - SBE- $\beta-C D$ ). All CDs were obtained from Cyclolab (Budapest, Hungary) with the exception of SBE- $\beta-C D$ - (Captisol $\left.{ }^{\circledR}\right)$ which was obtained from Cydex Corp. (USA).

For the determination from commercial pharmaceutical preparations we used Norvasc ${ }^{\circledR}$ tablets (Pfizer, USA) containing $5 \mathrm{mg}$ and $10 \mathrm{mg} \mathrm{AML}$, and Amlohexal (Hexal, Germany) containing $5 \mathrm{mg}$ and $10 \mathrm{mg}$ AML, obtained from a local pharmacy.

\section{Electrophoretic conditions}

The capillary was conditioned with $0.1 \mathrm{M} \mathrm{NaOH}$ for 30 minutes, purified water for 15 minutes and with the background electrolyte (BGE) for 15 minutes. Between runs, the capillary was preconditioned with $0.1 \mathrm{M} \mathrm{NaOH}$, purified water each for 1 minute and with the BGE, for 2 minutes.

BGE solutions were prepared dissolving the appropriate amount of buffer constituents in ultrapure water and adjusting the $\mathrm{pH}$ if necessary with $1 \mathrm{M} \mathrm{NaOH}$.

Stock solutions containing $1 \mathrm{mg} \mathrm{mL}^{-1}$ of the racemic AML were prepared in methanol, and diluted prior to use with the same solvent to the appropriate concentration. 
Both BGE and sample solutions were filtered through a $0.45 \mu \mathrm{m}$ pore size membrane filter and degassed in an ultrasonic bath for 5 minutes prior to use. All solutions were kept in the refrigerator when not in use.

Samples and standards were injected by hydrodynamic injection at the anodic end of the capillary, the detection taking place at the cathode. The initial electrophoretic conditions were the following: voltage + $20 \mathrm{kV}$, capillary temperature $25^{\circ} \mathrm{C}$, detector wavelengths 210,230 and $250 \mathrm{~nm}$, sample concentration $25 \mu \mathrm{g} \mathrm{mL}^{-1}$.

\section{Pharmaceutical sample preparation}

Ten tablets were weighed, ground and mixed in a mortar. An appropriate amount of the powder (equivalent to a AML tablet weight) was taken and dissolved in $10 \mathrm{~mL}$ methanol, sonicated in a ultrasonic water bath for 5 minutes and then diluted to $100 \mathrm{~mL}$ with methanol in a volumetric flask. The solutions were further diluted with methanol to the appropriate concentration before being introduced in the CE system for the determinations.

\section{RESULTS AND DISCUSSIONS}

\section{Preliminary analysis}

AML is a primary amine with a pKa value of 9.10, and can be detected over a large range of $\mathrm{pH}$ between 2.50 and 10.50. Initial electrophoretic separations were performed at four $\mathrm{pH}$ levels: 2.5, 5.0, 7.0 and 9,0. We noticed that the migration time of AML decreases with the increase of the $\mathrm{pH}$ value, and AML migrates ahead of the electroosmotic flow (EOF) at $\mathrm{pH}$ values above 5.0 , its apparent electrophoretic mobility being the sum of its effective electrophoretic mobility and the mobility of EOF. Under acidic $\mathrm{pH}$ conditions AML is positively charged, but as the $\mathrm{pH}$ becomes more alkaline, its effective mobility decreases because AML starts to deprotonate.

Next, we conducted a complex screening of the chiral selectors, by adding different types of CDs to the BGE and evaluating possible chiral interactions. During the CD screening process, initial concentration of $10 \mathrm{mM}$ neutral CDs were added to the buffer solution, while for charged CDs we added a concentration of $5 \mathrm{mM}$ in order to limit the increase of ionic strength which generated high currents and subsequent peak broadening. Stereoselective interactions were observed for the neutral $\alpha-C D, \beta-C D$, HP- $\beta-C D$ and $\mathrm{M}-\beta-\mathrm{CD}$ over a $\mathrm{pH}$ range between 2.5-5.0, and for the ionized CM- $\beta-\mathrm{CD}$ and SBE- $\beta-\mathrm{CD}$ over a $\mathrm{pH}$ range between 7.0-9.0.
The chiral interactions were evaluated taking into consideration the separation factors $(\alpha)$ calculated as the ratio of the migration times of the optical isomers, and the resolution $(\mathrm{R})$ obtained by the $\mathrm{R}=2\left(\mathrm{t}_{2}-\mathrm{t}_{1}\right) /\left(\mathrm{w}_{1}+\mathrm{w}_{2}\right)$ equation, where the migration times $\left(t_{1}\right.$ and $\left.t_{2}\right)$ and the peak-widths $\left(\mathrm{w}_{1}\right.$ and $\left.\mathrm{w}_{2}\right)$ were marked for the slow and fast migrating enantiomers, respectively.

The best results in the initial electrophoretic conditions were obtained at $\mathrm{pH} 9.0$ when using $\mathrm{CM}-\beta-\mathrm{CD}$ as chiral selector. CM- $\beta-C D$ is an anionic derivatized $\mathrm{CD}$ which exhibits chiral selectivity toward neutral and positively charged analytes, providing more recognition sites for chiral separation, especially in the separation of analytes bearing amine and hydroxyl substituent groups (Fang et al., 2017).

In $C E, C M-\beta-C D$ can be used as chiral selector in both the uncharged and charged form, depending on the $\mathrm{pH}$ of the BGE; as below $\mathrm{pH} 5.0$ it is uncharged while above $\mathrm{pH} 5.0$ because of the carboxylic group becomes negatively charged due to deprotonation (Maruszak et al., $2001)$. At $\mathrm{pH}$ values above 7.0, CM- $\beta-\mathrm{CD}$ is negatively charged and will move in the direction of EOF, while AML electrophoretic mobility is low, consequently stereoselective interactions can be observed.

\section{Optimization of the analytical method}

Experimental design methods for optimization of chiral resolution offer significant potential for rapid method development in CE. This approach has important advantages in CE, particularly for chiral separations, compared with the "ad hoc" univariate optimisation strategies. Conventional method optimization is based on changing one variable at a time, while keeping the other variables constant; this approach is the so-called "one-factor-at-a-time", and involves a relatively large number of individual experiments; therefore, the simultaneous variation of several factors have recently become widespread (Dejaegher, Vander Heyden, 2009).

In order to increase chiral resolution of AML enantiomers, a factorial analysis study was performed by orthogonal experimental design to analyze the effects and interactions of all parameters involved in the separation. The six examined variables included buffer concentration (25 mM, $50 \mathrm{mM}, 100 \mathrm{mM}$ ), buffer $\mathrm{pH}(7.0,8.0,9.0)$, $\mathrm{CD}$ concentration $(5 \mathrm{mM}, 10 \mathrm{mM}, 15 \mathrm{mM})$, temperature $\left(15^{\circ} \mathrm{C}, 17.5^{\circ} \mathrm{C}, 20{ }^{\circ} \mathrm{C}\right)$, voltage $(+20 \mathrm{kV},+25 \mathrm{kV}$, $+30 \mathrm{kV})$ and injection pressure ( $30 \mathrm{mbar} / \mathrm{sec}, 40 \mathrm{mbar} / \mathrm{sec}$, $50 \mathrm{mbar} / \mathrm{sec}$ ).

A standard orthogonal table L18 $\left(6^{3}\right)$ comprising 18 tests altogether was used to design the experiments in 
which the factors are varied in a systematic style in order to estimate the best conditions for the chiral separation of the AML enantiomers. As response factor, resolution values were recorded in each experiment (Table I).

The rank order of the studied variables was as follows: CD concentration, BGE pH, BGE concentration, applied voltage, injection pressure, capillary temperature. The importance of each factor was determined using ANOVA test of the experimental results; CD concentration and BGE $\mathrm{pH}$ showed significant effect on the resolution values in the investigated range under the studied conditions $\left(\mathrm{R}_{\mathrm{s}}=-0.92722+0.21917 \mathrm{pH}+0.087833 \mathrm{CD}\right.$ conc.). The effects of $\mathrm{CD}$ concentration and $\mathrm{BGE} \mathrm{pH}$ on the chiral resolution (Rs) was analyzed through a surface response methodology (Figure 2).

The results show that the optimal result was achieved when using $25 \mathrm{mM}$ phosphate BGE at $\mathrm{pH} 9.0,15 \mathrm{mM} \mathrm{CM}-$ $\beta$-CD as chiral selector, $25 \mathrm{kV}$ voltage, $15^{\circ} \mathrm{C}$ temperature,
$30 \mathrm{mbar} / 1$ second hydrodinamic injection. Combination of this parameter setup resulted in a chiral resolution value of 2.65, and a separation factor of 1.04 (Figure 3).

The migration order of the two enantiomers was determined by spiking the sample solution with the stock solution of the pure $S$-enantiomer. The first peak to pass the detector window was determined to be $S$-AML followed by $R$-AML.

\section{ANALYTICAL PERFORMANCE}

The validation of the developed method was performed in terms of, precision, accuracy, linearity, robustness, limit of detection (LOD) and limit of quantification (LOQ). The analytical performance of the method was verified according to ICH guidelines (Borman, Elder, 2017).

TABLE I - Orthogonal experimental design table for the AML chiral method optimization with corresponding resolution values

\begin{tabular}{|c|c|c|c|c|c|c|c|}
\hline Experiment & $\begin{array}{l}\text { BGE conc. } \\
\text { [mM] }\end{array}$ & BGE pH & $\begin{array}{l}\text { CD conc. } \\
{[\mathrm{mM}]}\end{array}$ & $\begin{array}{c}\text { Voltage } \\
{[\mathrm{kV}]}\end{array}$ & $\begin{array}{c}\text { Temperature } \\
{\left[{ }^{\circ} \mathrm{C}\right]}\end{array}$ & $\begin{array}{c}\text { Injection } \\
\text { parameter } \\
{[\text { mbar x s]s }}\end{array}$ & Rs \\
\hline 1 & 25 & 7.0 & 5 & 20 & 15 & $50 \times 1$ & 1.10 \\
\hline 2 & 50 & 8.0 & 10 & 25 & 15 & $30 \times 1$ & 2.00 \\
\hline 3 & 100 & 9.0 & 15 & 30 & 15 & $40 \times 1$ & 2.25 \\
\hline 4 & 50 & 9.0 & 5 & 20 & 17.5 & $30 \times 1$ & 1.25 \\
\hline 5 & 100 & 7.0 & 10 & 25 & 17.5 & $40 \times 1$ & 1.75 \\
\hline 6 & 25 & 8.0 & 15 & 30 & 17.5 & $50 \times 1$ & 2.00 \\
\hline 7 & 100 & 8.0 & 10 & 20 & 20 & $50 \times 1$ & 1.70 \\
\hline 8 & 25 & 9.0 & 15 & 25 & 20 & $30 \times 1$ & 2.60 \\
\hline 9 & 50 & 7.0 & 5 & 30 & 20 & $40 \times 1$ & 1.15 \\
\hline 10 & 50 & 8.0 & 15 & 20 & 15 & $40 \times 1$ & 2.00 \\
\hline 11 & 100 & 9.0 & 5 & 25 & 15 & $50 \times 1$ & 1.18 \\
\hline 12 & 25 & 7.0 & 10 & 30 & 15 & $30 \times 1$ & 1.55 \\
\hline 13 & 25 & 9.0 & 10 & 20 & 17.5 & $40 \times 1$ & 2.25 \\
\hline 14 & 50 & 7.0 & 15 & 25 & 17.5 & $50 \times 1$ & 1.85 \\
\hline 15 & 100 & 8.0 & 5 & 30 & 17.5 & $30 \times 1$ & 1.15 \\
\hline 16 & 100 & 7.0 & 15 & 20 & 20 & $30 \times 1$ & 1.60 \\
\hline 17 & 25 & 8.0 & 5 & 25 & 20 & $40 \times 1$ & 1.20 \\
\hline 18 & 50 & 9.0 & 10 & 30 & 20 & $50 \times 1$ & 2.10 \\
\hline Q1 & 1.79 & 1.50 & 1.17 & 1.65 & 1.68 & 1.70 & \\
\hline Q2 & 1.72 & 1.67 & 1.89 & 1.77 & 1.70 & 1.76 & \\
\hline Q3 & 1.60 & 1.94 & 2.05 & 1.81 & 1.73 & 1.83 & \\
\hline $\mathbf{R}$ & 0.19 & 0.44 & 0.88 & 0.16 & 0.05 & 0.13 & \\
\hline
\end{tabular}

Q1-Q3: the average resolution value under every level of the variable (Q1 - low level; Q2 - medium level; Q3 - high level); R: range value. the difference between the maximal and minimal value of the three levels for each parameter. 


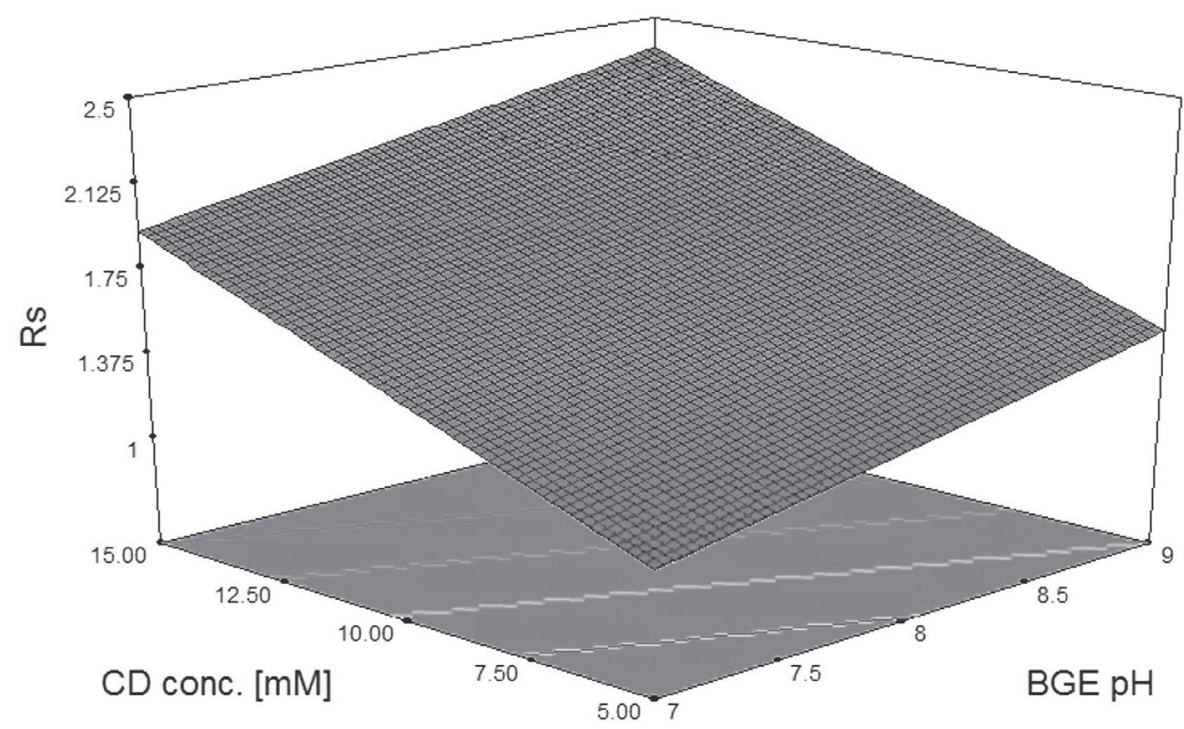

FIGURE 2 - The effects of $\mathrm{CD}$ concentration and BGE pH on the chiral resolution of AML enantiomers.

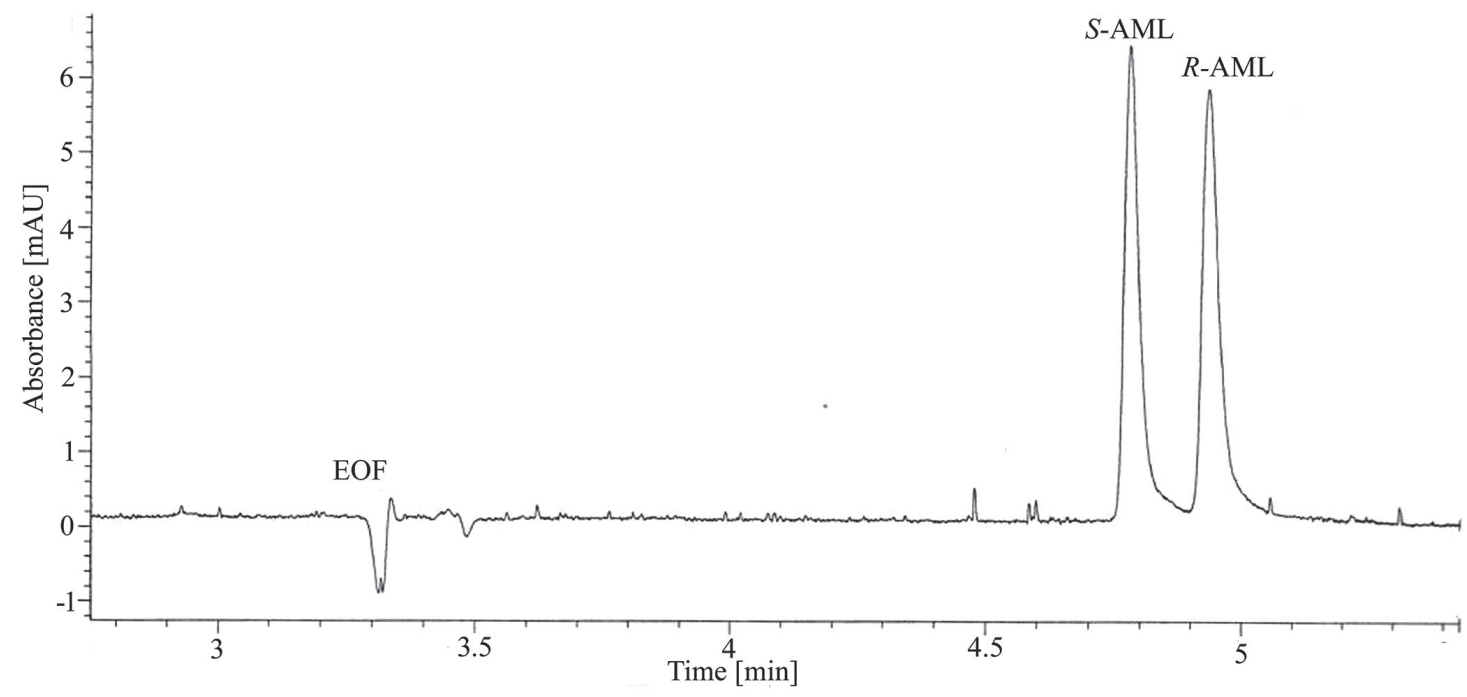

FIGURE 3 - Chiral separation of AML enantiomers under optimized electrophoretic conditions (analytical conditions: $25 \mathrm{mM}$ phosphate, $\mathrm{pH} 9.0,15 \mathrm{mM} \mathrm{CM}-\beta-\mathrm{CD},+25 \mathrm{kV}, 15{ }^{\circ} \mathrm{C}, 30 \mathrm{mbar} / 1$ second, UV $230 \mathrm{~nm}$ ).

\section{Precision}

Intra-day precision was verified by injecting consecutively racemic AML standards at three different concentrations $\left(25,50,100 \mu \mathrm{g} \mathrm{mL}^{-1}\right)$ six times during the same day. Inter-day precision was verified by injecting the same three different concentrations of the standard $(25$, $\left.50,100 \mu \mathrm{g} \mathrm{mL}^{-1}\right)$ six times per day for three consecutive days (Table II).

\section{Accuracy}

The accuracy of the method was carried out by standard addition method. An appropriate amount of racemic AML tablet powder was weighed and spiked with known amount of standard and each sample was analyzed in triplicates (Table III).

\section{Linearity}

A calibration curve was constructed at seven concentrations levels between $5-100 \mu \mathrm{g} \mathrm{mL}^{-1}$ of AML racemic standard. Each sample was injected three times. The linear regression line was calculated by the method of least squares (Table IV).

\section{LOD and LOQ}

LOD and LOQ were estimated as: standard deviation of regression equation/slope of the regression 
TABLE II - Intra-day and inter-day reproductibility data for repeated injections of different concentrations of racemic AML standard

\begin{tabular}{|c|c|c|c|c|}
\hline \multirow{3}{*}{ Factor conc. $\left(\mu \mathrm{g} \mathrm{mL} \mathrm{L}^{-1}\right)$} & \multicolumn{4}{|c|}{ Relative standard deviation - RSD (\%) } \\
\hline & \multicolumn{2}{|c|}{ Migration time (min) } & \multicolumn{2}{|c|}{ Peak areas } \\
\hline & $S$-AML & $R$-AML & $S$-AML & $R$-AML \\
\hline \multicolumn{5}{|l|}{ Intra-day precision $(\mathrm{n}=6)$} \\
\hline 25 & 0.03 & 0.04 & 0.97 & 0.94 \\
\hline 50 & 0.05 & 0.05 & 1.22 & 1.23 \\
\hline 100 & 0.08 & 0.10 & 1.27 & 1.32 \\
\hline \multicolumn{5}{|c|}{ Inter-day precision $(\mathrm{n}=18)$} \\
\hline 25 & 0.20 & 0.25 & 1.27 & 1.45 \\
\hline 50 & 0.25 & 0.30 & 1.38 & 1.50 \\
\hline 100 & 0.32 & 0.38 & 1.50 & 1.52 \\
\hline
\end{tabular}

TABLE III - Recovery values obtained from the determination of AML spiked with different levels of standards

\begin{tabular}{ccc}
\hline \multirow{2}{*}{$\begin{array}{c}\text { Racemic AML } \\
\left(\boldsymbol{\mu g} \mathbf{~ m L}^{-1}\right)\end{array}$} & \multicolumn{2}{c}{ Mean recovery $(\% \pm$ SD) } \\
\cline { 2 - 3 } & $\boldsymbol{S}$-AML & $\boldsymbol{R}$-AML \\
\hline 25 & $98.52 \pm 1.41$ & $98.64 \pm 1.61$ \\
50 & $99.11 \pm 1.80$ & $98.92 \pm 1.12$ \\
75 & $99.13 \pm 1.52$ & $99.01 \pm 1.44$ \\
\hline
\end{tabular}

equation multiplied by 3.3 and 10 , respectively (Table IV).

\section{Robustness}

The robustness of the method was studied using Plackett-Burmann statistical experimental design (Van der Heyden et al., 2001). Five variables were chosen including:
BGE concentration $(20 \mathrm{mM}, 30 \mathrm{mM})$, BGE $\mathrm{pH}(8.5,9.5)$, CD concentration (14 mM, $16 \mathrm{mM})$, capillary temperature $\left(13{ }^{\circ} \mathrm{C}, 17^{\circ} \mathrm{C}\right)$, applied voltage $(23 \mathrm{kV}, 27 \mathrm{kV})$; each value investigated at a lower and an upper level with regard to the optimized values. As response factor chiral resolution of the enantiomers was recorded. According to the statistical evaluation of the data none of the five studied variables had a significant effect on the response factor.

\section{Determination from pharmaceutical products}

The proposed CE method was applied in pharmaceutical analysis to determine the enantiomeric content of AML in original (Norvasc) and generic (Amlohexal) commercial pharmaceutical products. The content of AML, obtained by the proposed method, was in a good agreement with that declared by the manufacturers (Table V). No interference from the

TABLE IV - Calibration data and LOD/LOQ values for AML chiral separation (concentration range: $5-100 \mu \mathrm{g} \mathrm{mL}^{-1}, \mathrm{n}=3, \mathrm{n}=3$ )

\begin{tabular}{ccccc}
\hline Enantiomers & Regression equation & Correlation coefficient & $\mathbf{L O D}\left(\boldsymbol{\mu g} \mathbf{~ m L}^{-1}\right)$ & $\mathbf{L O Q}\left(\boldsymbol{\mu g} \mathbf{~ m L}^{-1}\right)$ \\
\hline $\boldsymbol{S}$-AML & $\mathrm{y}=12.17 \mathrm{x}-0.171$ & 0.999 & 0.27 & 0.80 \\
$\boldsymbol{R}$-AML & $\mathrm{y}=12.192 \mathrm{x}+0.8158$ & 0.9987 & 0.32 & 0.96 \\
\hline
\end{tabular}

TABLE V - Determination of AML enantiomers from pharmaceutical preparations

\begin{tabular}{lccccc}
\hline \multirow{2}{*}{ Pharmaceutical product } & \multicolumn{2}{c}{ Declared enantiomer quantity $(\mathbf{m g})$} & & \multicolumn{2}{c}{ Found enantiomer quantity (mg) \pm SD (n =3) } \\
\cline { 2 - 3 } \cline { 5 - 6 } & $\boldsymbol{S}$-AML & $\boldsymbol{R}$-AML & & $\boldsymbol{S}$-AML & $\boldsymbol{R}$-AML \\
\hline Norvasc (10 mg AML) & 5 & 5 & & $4.97 \pm 0.35$ & $5.06 \pm 0.35$ \\
Norvasc (5 mg AML) & 2.5 & 2.5 & & $2.50 \pm 0.45$ & $2.52 \pm 0.31$ \\
Amlohexal (10 mg AML) & 5 & 5 & & $5.09 \pm 0.40$ & $5.29 \pm 0.25$ \\
Amlohexal (5 mg AML) & 2.5 & 2.5 & & $2.56 \pm 0.40$ & $2.53 \pm 0.30$ \\
\hline
\end{tabular}


drug formulation excipients could be observed on the electropherograms, this demonstrates the specificity of the method and its suitability to be used in routine chiral analysis (Figure 4).
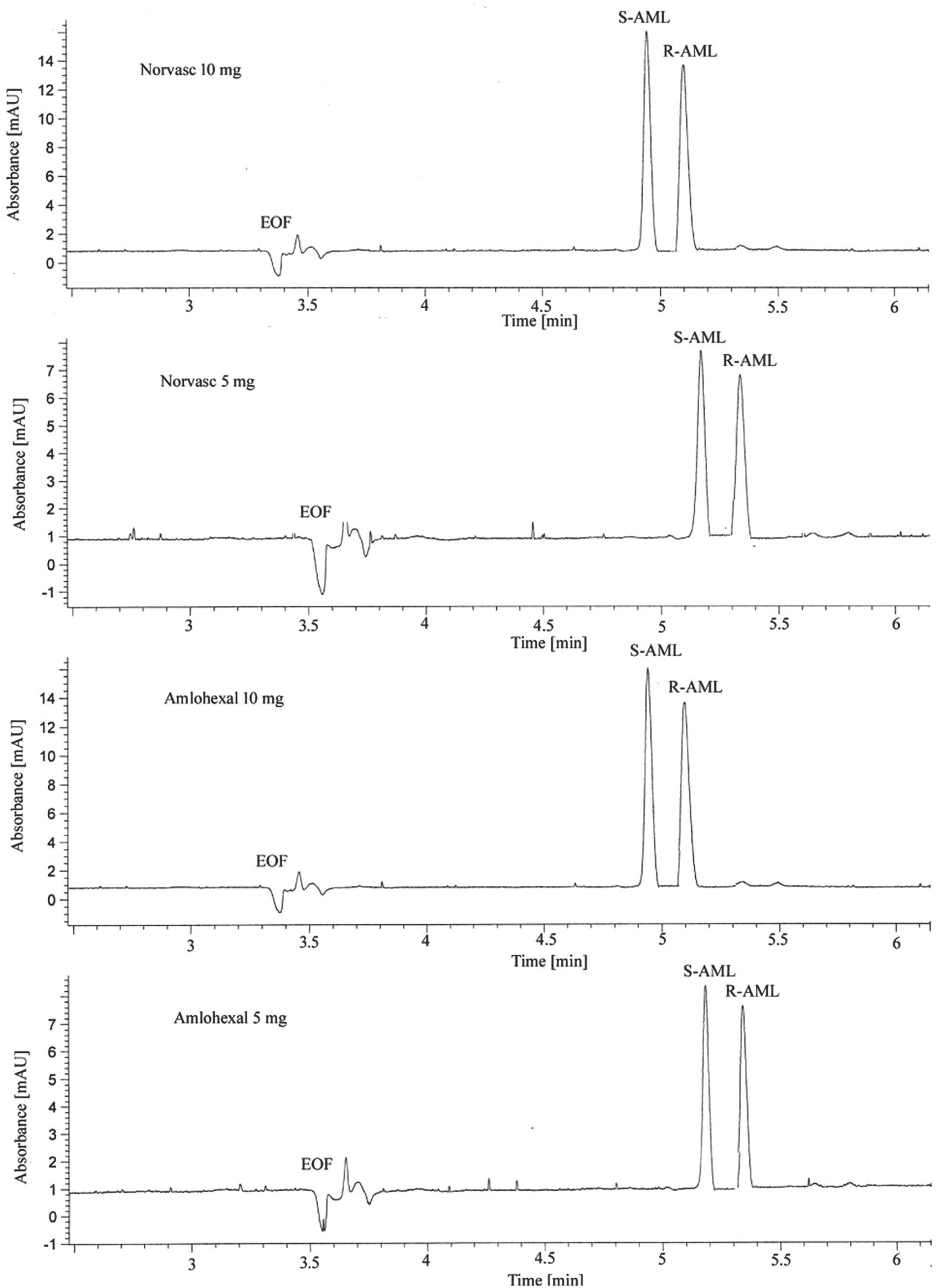

FIGURE 4 - Electropherograms from the enantioselective determination of AML in commercial pharmaceutical preparations (analytical conditions: $25 \mathrm{mM}$ phosphate, $\mathrm{pH} 9.0,15 \mathrm{mM} \mathrm{CM}-\beta-\mathrm{CD},+25 \mathrm{kV}, 15^{\circ} \mathrm{C}, 30 \mathrm{mbar} / 1 \mathrm{~second}, 230 \mathrm{~nm}$ ). 


\section{CONCLUSIONS}

It can be concluded that our optimized CE method is useful for routine pharmaceutical applications for the chiral separation of AML with benefits of its effectivity, simplicity, cost and enhanced analytical value.

The use of an alkaine BGE and a anionic CD as chiral selector generated short analysis time and high chiral resolutions. BGE concentration and $\mathrm{pH}, \mathrm{CD}$ concentration, capillary temperature, applied voltage and injection parameters, were optimized by using orthogonal experimental design to develop a CE system, practically suitable for the chiral discrimination of AML enantiomers in less then 5 minutes.

By comparison with other analytical methods already published for the chiral separation of AML enantiomers our method offers the advantages of a shorter migration time (Small et al., 1995; Fakhari et al., 2008) and more simple electrophoretic conditions (Mikus et al., 2008, Zandkarimi et al., 2009).

The new method was successfully used for the determination of enantiomeric composition of AML in various commercial pharmaceutical preparations. The results confirmed the racemic composition of the active compound in the pharmaceuticals.

\section{REFERENCES}

Borman P, Elder S. Q2(R1) Validation of analytical procedures in ICH Quality Guidelines: An immplementaion guide, 2017. p. 127-165.

Chen J, Du Y, Zhu F, Chen B. Evaluation of the enantioselectivity of glycogen-based dual chiral selector systems towards basic drugs in capillary electrophoresis. J Chromatogr A. 2010;1217(45):7158-7163.

Deeb SE, Wätzig H, El-Hady DA, Albishri HM, de Griend CS, Scriba GK. Recent advances in capillary electrophoretic migration techniques for pharmaceutical analysis. Electrophoresis. 2014;35(1):170-189.

Deeb ES, Wätzig H, Abd El-Hady D, Sänger-van de Griend C, Scriba GK. Recent advances in capillary electrophoretic migration techniques for pharmaceutical analysis (2013-2015). Electrophoresis. 2016;37(12):1591-1608.

Dejaegher B, Vander Heyden Y. The use of experimental design in separation science. Acta Chromatographica. 2009;21(2):161201.
Fakhari AR, Nojavan S, Haghgoo S, Mohammadi A. Development of a stability-indicating CE assay for the determination of amlodipine enantiomers in commercial tablets. Electrophoresis. 2008;29(22):4583-4592.

Fang L, Du Y, Hu X, Luo L, Guo X, Guo X, Yu J. Carboxymethyl $\beta$-cyclodextrin as chiral selector in capillary electrophoresis: Enantioseparation of 16 basic chiral drugs and its chiral recognition mechanism associated with drugs' structural features. Biomed Chromatogr. 2017;31(11):e3991.

Hancu G, Budău M, Kántor LK, Cârje A. Cyclodextrine screening for the chiral separation of amlodipine enantiomers by capillary electrophoresis. Adv Pharm Bull. 2015;5(1):35-40.

Hotha KK, Roychowdhury S, Mullangi R, Ravindranath LK. Rapid quantification of amlodipine enantiomers in human plasma by LC-MS/MS: Application to a clinical pharmacokinetic study. Biomed Chromatogr. 2013;27(9):1192-1199.

Li ZW, Jia X, Xu CM, Liu L, Fu DC. Chiral separation of amlodipine and its enantiomer on a molecularly imprinted polymer-based stationary phase. Adv Mater Res. 2013;706708:36-39.

Luksa J, Josic D, Kremser M, Kopitar Z, Milutinovic S. Pharmacokinetic behaviour of R-(+)- and S-(-)-amlodipine after single enantiomer administration. J Chromatogr B. 1997;703(12):185-193.

Maruszak W, Trojanowicz M, Margasińska M, Engelhardt H. Application of carboxymethyl- $\beta$-cyclodextrin as a chiral selector in capillary electrophoresis for enantiomer separation of selected neurotransmitters. J Chromatogr A. 2001;926(2):327-336.

Mikus P, Marakova K, Marak J, Nemec I, Valaskova I, Havranek E. Direct quantitative determination of amlodipine enantiomers in urine samples for pharmacokinetic study using on-line coupled isotachophoresis-capillary zone electrophoresis separation method with diode array detection. J Chromatogr B. 2008;875(1):266-272.

Murdoch D, Heel RC. Amlodipine. A review of its pharmacodynamic and pharmacokinetic properties, and therapeutic use in cardiovascular disease. Drugs. 1991;41(3):478505.

Owens PK, Fell AF, Coleman MW, Berridge JC. Effect of charged and uncharged chiral additives on the resolution of amlodipine enantiomers in liquid chromatography and capillary electrophoresis. J Chromatogr A. 1998;797(1-2):187-195. 
Nojavan S, Pourmoslemi S, Behdad H, Fakhari AR, Mohammadi A. Application of maltodextrin as chiral selector in capillary electrophoresis for quantification of amlodipine enantiomers in commercial tablets. Chirality. 2014;26(8):394-399.

Scriba GK, Jac P. Enantioseparations by capillary electrophoresis using cyclodextrins as chiral selectors. Methods Mol Biol. 2013;970:271-287.

Small SS, Fell AF, Coleman MW, Berridge JC. Central composite of ruggedness and design for the rapid optimisation chiral separation of amlodipine in capillary electrophoresis. Chirality. 1995;7(4):226-234.

Vander Heyden Y, Nijhuis A, Smeyers-Verbeke J, Vandeginste BG, Massart DL. Guidance for robustness/ruggedness tests in method validation. J Pharm Biomed Anal. 2001;24(5-6):723753.
Wang R, Jia Z, Fan JJ, Chen LR, Xie H, Ma J, Ge X, Zhang Q, Ao Y, Wang J. CE, with hydroxypropyl- $\beta$-cyclodextrin as chiral selector, for separation and determination of the enantiomers of amlodipine in the serum of hypertension patients. Chromatographia. 2007;65(9-10):575-579.

Xie J, Tan Q, Yang L, Lai S, Tang S, Cai C, Chen X. A simple and rapid method for chiral separation of amlodipine using dual chiral mobile phase additives. Anal Meth. 2014;6:4408-4413.

Zandkarimi M, Shafaati A, Foroutan SM, Lucy CA, Rapid enantioseparation of amlodipine by highly sulfated cyclodextrins using short-end injection capillary electrophoresis. DARU. 2009;17(4):269-275.

Zandkarimi M, Shafaati A, Foroutan SM, Lucy CA. Improvement of electrophoretic enantioseparation of amlodipine by polybrene. Iran J Pharm Res. 2012;11(1):129-136.

Received for publication on $03^{\text {rd }}$ April 2018 Accepted for publication on $24^{\text {th }}$ September 2018 